\title{
Fingerprint Ridge Orientation Extraction: A Review of State of the Art Techniques
}

\author{
Vidyadevi G. Biradar \\ Nitte Meenakshi Institute of Technology
}

\author{
Sarojadevi $\mathrm{H}$. \\ Nitte Meenakshi Institute of Technology
}

\begin{abstract}
Personal identification based on fingerprints is very popular compared to identification based on other biometric features like iris, gait and face etc. Performance of automatic fingerprints identification systems depends upon the quality of fingerprints. Extraction of fingerprints features in poor quality fingerprints is challenging task. Accurate measurement of fingerprints feature improves the accuracy of identification systems. Fingerprints consists of ridge and valley structures and offers different types of features, they are categorized as level 1 , level 2 and level 3 features. Level 1 features are singular points which are used for fingerprints registration, classification etc. Level 2 features are ridge features like minutiae points, ridge orientation etc., and commercially available fingerprint recognition systems are based on level 2 features. Level 3 features include sweat pores, incipient ridges etc. Among these features ridge orientation is used for fingerprint enhancement, fingerprint classification, indexing and fingerprint segmentation. This paper provides an overview of existing state of the art techniques for ridge orientation estimation.
\end{abstract}

\section{General Terms}

Fingerprints Recognition, Biometrics, Ridge Orientation, Gradients, FOMFE, CDT et. al.

\section{Keywords}

Fingerprint recognition, Ridge orientation, combinational model, Latent, Gradients, Singular points.

\section{INTRODUCTION}

Personal identification systems based on fingerprints are the most popular and proven systems, which have been successfully deployed in number of applications ranging from simple access control to convicting criminal by forensic and law agencies. The main advantages of fingerprint biometric are, fingerprints are unique nature and are different even for twins, requires less storage space and availability of low cost fingerprints sensors.

Fingerprints consist of ridge and valley structures and according to the characteristics of these structures fingerprint features are classified into three types viz., level 1, level 2 and level 3 features (see Figure 1 and Figure 2). Level 1 features are singular points representing core and delta - around singular points ridges have high curvature [1]. Singular points are useful in fingerprints registration process during the comparison of given two fingerprints based on neighborhood similarity. Also singular points are useful for fingerprints indexing in the database. Level 2 features are minutiae points; these represent discontinuities in the ridge flows such as ridge bifurcation and ridge ending. Automatic fingerprint identification systems based on minutiae are the most widely used and these are accepted by law agencies. Level 3 features include incipient ridges, short ridges and sweat pores etc. These features are used in partial fingerprints recognition and liveliness detection etc.

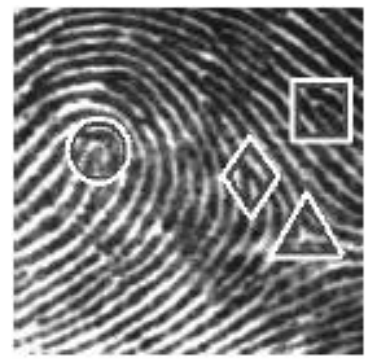

Fig 1: Level 1 features: core point (in circle), delta point (in triangle), minutiae-ridge ending (in square), and minutiae-ridge bifurcation (in diamond).

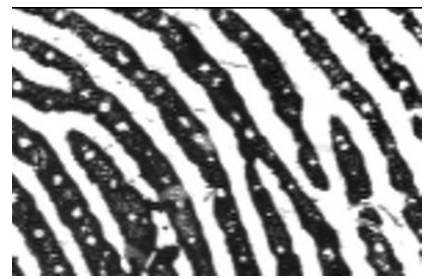

Fig 2: Level 2 features: Sweat pores

Fingerprints recognition systems consists of four major steps as given below.

1. Pre-processing - this involves removal of noise and improvement of contrast of ridge patterns.

2. Feature extraction - this stage extracts appropriate features and creates templates which are stored in the database. Any two fingerprints are compared in terms of features for matching purpose. The process of feature selection, extraction and representation is very important in the improvement of the performance of fingerprints recognition systems. Features should possess characteristics of distinctiveness, enable compact representation and use less storage space.

3. Post processing - in some cases features extracted will be spurious features, therefore a process of feature validation is applied.

4. Fingerprint matching - this is search operation and retrieves nearest matching fingerprints from the database for a given input fingerprint. Methods of feature selection, template generation and matching are interdependent. In order to eliminate such dependency and exploit strengths of various algorithms lot of encouragement is given for development of open algorithms. 
Fingerprints recognition systems operate in two modes they are verification mode and identification mode. Firstly, in Verification mode- Given input fingerprint is compared with the fingerprints database and input fingerprint is generally one of are already stored/enrolled fingerprints in the database through the enrolment process. Identification mode- systems validate whether the claim for identity is true or false [1]. Fingerprint verifications are mainly deployed for civilian applications such as access control, wherein ensures that an unauthorized person does not get access to a resource. Secondly, fingerprints identification systems are essentially recognition systems, where an input fingerprint is compared with the fingerprints database, the given input fingerprints may not be necessarily an enrolled fingerprint, these systems find applications in criminal identification.

Fingerprints recognition systems have evolved to a large extent and researchers have proposed numerous proven methods. However recent research literature is evident that still there is a need for development of more robust systems. Fingerprint recognition systems deployed for civilian applications perform well for good quality fingerprints, but they exhibit poor performance for noisy fingerprints. Fingerprints collected from an uncontrolled environment are often of poor quality due to some artifacts. Also partial fingerprints and latent fingerprints contain complex background, in such cases performance of fingerprints recognition systems need to be enhanced. In practice, fingerprint recognition system software involve interaction from fingerprints examiners to manually mark some features (singular points, minutiae points and ridge orientations) in case of challenged fingerprints, therefore it is clear that existing fingerprint recognition systems are not fully automatic. Thus fingerprint recognition still remains as an active research area.
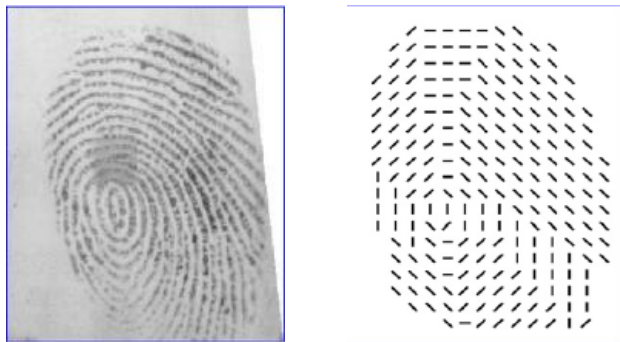

Fig 3: (a) fingerprint image (b) Orientation image

Fingerprints recognition systems are improved by optimizing the algorithms used in pre processing, feature extraction and matching. Appropriate feature selection and extraction is very important for performance improvement of fingerprints recognition system. Ridge orientation of fingerprint (see Figure 3 ) is a very useful feature. Ridge orientation feature is used for fingerprints enhancement, segmentation, indexing and matching. Papers [9] [14] [18] [20] [21] have presented fingerprint image enhancement algorithms based on ridge orientation. Ridge patterns can be enhanced through a bank of filters tuned to specific frequencies for different locations in the fingerprints based on ridge orientation. In papers [1] [7] [9] ridge orientation is used for singular points detection.

There exists numerous methods for fingerprints indexing and classification based on ridge orientation estimation, papers [3][9][12] and many others in literature have presented indexing, classification and matching methods. Indexing is a process of arranging fingerprints templates into different bins. Those belonging to a particular bin share some common features and they are yet different from one another. Fingerprint classification aids in indexing, there are many proven methods of classification based on orientation. Fingerprint indexing reduces the search space and speeds up the matching process. The speed of fingerprint recognition decreases with increase in the size of database. Fingerprints database stores templates and smaller the size of the template compact is the representation, offers benefits of lower storage and better matching speed.

This paper is organized as follows. Section 2 introduces local ridge orientation estimation methods. Section 3 introduces global ridge orientation extraction methods. In Section 4 provides comparative analysis of ridge orientation extraction methods and Section 5 concludes the paper.

\section{LOCAL METHODS FOR ORIENTATION EXTRACTION}

There are numerous methods for orientation extraction viz. Filter-bank, waveform projection and spectral estimation, gradient based methods and model based methods. Filter bank and projection methods are computationally expensive and inaccurate compared to gradient based methods. Gradient based methods are most simple and accurate for good quality fingerprints; however they are not robust to the noise. Lot of research is done in the past to develop algorithms to deal with the limitations of gradient methods.

There exist several other methods in which ridge orientation estimation is done through mathematical modeling. These represent ridge orientation at global level. Most of the global methods need prior information on singular points and initial coarse orientation estimation in fingerprints. Gradient based methods are computationally efficient compared to other methods; however they are sensitive to noise. Papers [2] [6] [8] [10] [11] [12] [13] [14] [17] [20][21] have been presented to improve upon gradient based methods, each of the paper has its method which is described below. Paper [2] has presented ridge orientation estimation method based on principal component analysis, in which accuracy is similar to gradient based methods. In order to reduce the noise in a image, in general a low pass filtering is applied, but this may result into lose of features in high curvature areas such as region around singular points in fingerprint images. Thus paper [6] has suggested a robust method of orientation estimation using adaptive Gaussian filter, it computes orientation at different scales and then the results are combined to obtain best orientation. This method is robust to noise and satisfactory for fingerprints that contain scratchy regions.

In the direction of developing robust algorithms, authors of paper [8] have presented a method based on machine. In this method the correctness of orientation estimation is verified through neural network. Paper [10] describes an algorithm in which orientation is estimated considering four overlapping regions in fingerprint image block and best orientation is selected using a voting scheme and reliability measures. Gradient based orientation estimation methods use differentiation operator, these operators do not provide flexibility for scale selection and provide biased orientation estimates. Paper [11] has given a new approach where image orientation is obtained with an integration operator which gives comparatively better result.

Paper [12] presented algorithm based on interpolation. Fingerprint image is divided into a set of valid and invalid regions based on orientation coherence and orientation in 
interpolated using Constrained Delaunay Triangulation method. Paper [13] describes a method of ridge orientation estimation, wherein the image is first preprocessed and then divided into number of blocks and in each block a significant ridge is identified through a pulse coupled neural network(PCNN), followed by which a dominant block direction is obtained using projective distance variance method. This method is computationally less expensive and robust to the noise.

Authors of paper [14] have proposed a method of computation of orientation field by analyzing a group of parallel ridge structures, where ridges are identified using rudimentary line tracing algorithm. Paper [17] gives an algorithm, in which the orientation is estimated in two steps. Firstly fingerprint image regions are either identified as certain regions or uncertain regions based noise and singular points and other artifacts. Orientation estimation in certain regions is computed using gradient method, then in uncertain regions orientation is interpolated using certain regions. This method offers better accuracy compared to gradient methods.

It is evident from the history that forensic agencies take support of Automatic fingerprints identification for criminal conviction. Fingerprints such as latents, collected from the crime scene are often unclear, and contain complex background structures. Ridge orientation estimation becomes very challenging in such cases. The focus of the research in the past was developing ridge orientation extraction algorithms for live scan or rolled fingerprints which are not suitable for latents. Recently, author of paper [20] presented a method appropriate for latents. This method of ridge orientation which is based on ridge pattern templates and uses a concept of dictionary; here a dictionary of ridge pattern patches is maintained in a dictionary. Orientation in uncertain regions is computed using nearest matching orientation patch from the dictionary. The results presented in this paper indicate that this method is superior to all previous methods from the point of accuracy and outperforms manual orientation marking for good quality fingerprints. In paper [21] proposes a method on ternization process which is applied for ridge orientation estimation in which fingerprint is divided into a set of three different blocks. They are white, black and gray, white block posses accurate orientation estimation, black block contains false orientation estimation, whereas gray is uncertain block whose orientations are classified either as belonging to white or black block. Then uses a neural network is designed and trained to respond strongly to true orientations and weakly to false orientations.

\section{GLOBAL METHODS FOR ORIENTATION EXTRACTION}

Local ridge orientation methods are simple and give accurate orientation estimation for good quality fingerprints. Lot many methods are explored to improve the accuracy of local methods, however they are not satisfactory for poor quality fingerprints. In poor quality fingerprints ridge structures are not clear, may contain scars or ridges may be covered with artifacts. In order to overcome the limitations of local orientation estimation methods another approach based on mathematical modeling are used, these are the global methods. In global methods firstly coarse orientation estimation is computed using gradient methods, and then the modeling parameters are fitted. A general model to represent ridge orientation of entire fingerprint is not sufficient and poses problems around singular points and other high curvature areas, therefore some methods model ridge orientation with two models, one is for global orientation estimation and another for region around singular points and high curvature areas, and then the results of both the models are combined. In such methods it is required to identify the location of singular points and high curvature area around them. Previous research has presented number of methods for singular points, yet they are not fully satisfactory. Thus detection of singular points is another challenging task. Any error in singular points detection may also lead to erroneous orientation. In practice many automatic fingerprint identification systems incorporate manual marking of singular points with fingerprint examiners. Therefore automatic fingerprint identification systems are not fully automatic. Research work carried in papers [3] [4] [5] [7] [9] [15] [16] [18] have presented ridge orientation extraction methods that are based on mathematical modeling.

Zero pole model and piecewise linear approximation models does not utilize prior information on singular points for improving the accuracy of ridge orientation estimation methods. Authors of Paper [3] and [4] presents combinational model methods for improving ridge orientation extraction, where ridge orientation at global level is modeled using polynomial model and estimation around singular points is improved by using point charge model and results of both the models are combined with a weighted function, these methods give satisfactory results for regions that are near or away from the singular points. Also these provide compact representation so need storage space. Paper [5] presents yet another method using non linear phase portrait model. In order to improve the accuracy of orientation estimation high order portrait is used for global representation and low order portrait is used for regions around singular points. In paper [7] we find a method of simultaneously computing singular points as well update ridge orientation estimation through dynamic updating strategy.

Works presented in paper [9] do not need any prior knowledge on singular points and still gives accurate estimation. In this method ridge orientation is represented using 2D Fourier series expansions. This method incurs less computational load and provides compact representation. Papers [15] and [16] present a statistical model, here ridge orientation is modeled using Legendre polynomials and parameter fitting is done using Levenberg-Marquard (LM) algorithm. This method iteratively tunes orientation estimation. This method does not depend on singular points and hence does not require any manual interaction. The most critical factor in polynomial methods is fixing the order of the polynomial.

In case of latent fingerprints estimation of ridge orientation is challenging, paper [18] has presented a method of enhancing the fingerprint image using ridge orientation in which ridge orientation is estimated using Short Time Fourier Transform. The results indicate that there is a significant improvement in the accuracy of fingerprint recognition systems. This method incorporates manual marking for region of interest and also uses singular points information.

\section{QUALITATIVE ANALYSIS OF FINGERPRINT RIDGE ORIENTATION EXTRACTION METHODS}

Fingerprint ridge orientation feature is very essential feature used in fingerprint recognition/identification systems. Accurate estimation of ridge orientation is a challenging task especially in poor quality fingerprints. This section presents different approaches to ridge orientation extraction methods 
including both local and global methods and highlights the advantages and disadvantages of various methods.

Table 1. Gives detailed comparison of local methods of fingerprint ridge orientation estimation. The most widely used ridge orientation extraction methods are based on fingerprints image gradients. These are simple and elegant methods; however they are sensitive to noise.

Table 1. Comparative Analysis of local methods of ridge orientation estimation

\begin{tabular}{|c|c|c|c|}
\hline Authors & Approach & Advantages & Disadvantages \\
\hline $\begin{array}{l}\text { Asker M. } \\
\text { Bazen and } \\
\text { Sabih H. } \\
\text { Gerez } \\
{[2002][2]}\end{array}$ & $\begin{array}{l}\text { Principal } \\
\text { component } \\
\text { analysis. } \\
\text { Singular } \\
\text { point } \\
\text { detection } \\
\text { based of } \\
\text { Poincare } \\
\text { index. }\end{array}$ & $\begin{array}{l}\text { Accurate } \\
\text { detection of } \\
\text { singular } \\
\text { points. }\end{array}$ & $\begin{array}{l}\text { Not } \\
\text { satisfactory for } \\
\text { noisy images. }\end{array}$ \\
\hline $\begin{array}{l}\text { Asker M. } \\
\text { Bazen, } \\
\text { Niek J. } \\
\text { Bouman, } \\
\text { and } \\
\text { Raymond } \\
\text { N.J. } \\
\text { Veldhui } \\
\text { [2004][6] }\end{array}$ & $\begin{array}{l}\text { Multiple } \\
\text { scales } \\
\text { orientation } \\
\text { computation. }\end{array}$ & $\begin{array}{l}\text { Provides } \\
\text { accurate } \\
\text { estimates in } \\
\text { scratchy } \\
\text { regions and } \\
\text { regions } \\
\text { around } \\
\text { singular } \\
\text { points. }\end{array}$ & $\begin{array}{l}\text { More } \\
\text { computational } \\
\text { load. }\end{array}$ \\
\hline $\begin{array}{l}\text { En Zhu, } \\
\text { Jian-Ping } \\
\text { Yin, } \\
\text { Guo-Min } \\
\text { Zhang, } \\
\text { Chun-Feng } \\
\text { Hu } \\
{[2006][8]}\end{array}$ & $\begin{array}{l}\text { Neural } \\
\text { network }\end{array}$ & $\begin{array}{l}\text { Better } \\
\text { compared to } \\
\text { gradient } \\
\text { based } \\
\text { methods. }\end{array}$ & $\begin{array}{l}\text { Not very much } \\
\text { robust to noise. }\end{array}$ \\
\hline $\begin{array}{l}\text { Yi Wang, } \\
\text { Jiankun Hu, } \\
\text { Fengling } \\
\text { Han } \\
{[2007][10]}\end{array}$ & $\begin{array}{l}\text { Gradient } \\
\text { based } \\
\text { method for } \\
\text { orientation } \\
\text { estimation. }\end{array}$ & $\begin{array}{l}\text { Computation } \\
\text { cost is less. }\end{array}$ & $\begin{array}{l}\text { Not robust to } \\
\text { noise. }\end{array}$ \\
\hline $\begin{array}{l}\text { Xudong } \\
\text { Jiang } \\
{[2007][11]}\end{array}$ & $\begin{array}{l}\text { Applies } \\
\text { image } \\
\text { integration } \\
\text { to estimate } \\
\text { orientation } \\
\text { field. }\end{array}$ & $\begin{array}{l}\text { Accurate } \\
\text { compared to } \\
\text { gradient } \\
\text { methods. } \\
\text { Offers } \\
\text { flexibility } \\
\text { for scale } \\
\text { selection. }\end{array}$ & $\begin{array}{l}\text { Needs } \\
\text { optimization } \\
\text { Un satisfactory } \\
\text { for noisy } \\
\text { images. }\end{array}$ \\
\hline $\begin{array}{l}\text { Qinzhi } \\
\text { Zhang, } \\
\text { Hong Yan } \\
{[2007][12]}\end{array}$ & $\begin{array}{l}\text { Orientation } \\
\text { is } \\
\text { interpolated } \\
\text { through } \\
\text { CDT. }\end{array}$ & $\begin{array}{l}\text { Does not use } \\
\text { singular } \\
\text { points. } \\
\text { Computation } \\
\text { ally simple. }\end{array}$ & $\begin{array}{l}\text { Unsatisfactory } \\
\text { for partial } \\
\text { fingerprints. } \\
\text { Produces } \\
\text { distorted } \\
\text { orientation near } \\
\text { image edges. }\end{array}$ \\
\hline
\end{tabular}

\begin{tabular}{|c|c|c|c|}
\hline $\begin{array}{l}\text { Luping Ji, } \\
\text { Zhang Yi } \\
{[2008][13]}\end{array}$ & $\begin{array}{l}\text { Uses neuron } \\
\text { pulses of } \\
\text { pulse } \\
\text { coupled } \\
\text { neural } \\
\text { network } \\
(\mathrm{PCNN}) .\end{array}$ & $\begin{array}{l}\begin{array}{l}\text { Provides } \\
\text { good } \\
\text { accuracy. }\end{array} \\
\text { Low } \\
\text { computation } \\
\text { al expense. } \\
\text { Robust to } \\
\text { noise. }\end{array}$ & $\begin{array}{l}\text { Not very robust } \\
\text { to noise. }\end{array}$ \\
\hline $\begin{array}{l}\text { Carsten } \\
\text { Gottschlich, } \\
\text { Preda } \\
\text { Mihailescu } \\
\text { and } \\
\text { Axel Munk } \\
\text { [2009][14] }\end{array}$ & $\begin{array}{l}\text { Extrapolates } \\
\text { ridge using } \\
\text { orientation } \\
\text { from smooth } \\
\text { regions. }\end{array}$ & $\begin{array}{l}\text { Robust } \\
\text { against } \\
\text { scars, } \\
\text { contaminatio } \\
\mathrm{n}, \text { moisture } \\
\text { or dryness of } \\
\text { the finger. }\end{array}$ & $\begin{array}{l}\text { Greater } \\
\text { computational } \\
\text { complexity. }\end{array}$ \\
\hline $\begin{array}{l}\text { Limin Liu , } \\
\text { Tian-Shyr } \\
\text { Dai } \\
{[2011][17]}\end{array}$ & Interpolation & $\begin{array}{l}\text { Accurate } \\
\text { compared to } \\
\text { gradients. }\end{array}$ & $\begin{array}{l}\text { Not very much } \\
\text { robust to noise. }\end{array}$ \\
\hline $\begin{array}{l}\text { Jianjiang } \\
\text { Feng, } \\
\text { Jie Zhou, } \\
\text { Anil K. Jain } \\
\text { [2013][20] }\end{array}$ & $\begin{array}{l}\text { Dictionary } \\
\text { method. }\end{array}$ & $\begin{array}{l}\text { Out } \\
\text { performs } \\
\text { All existing } \\
\text { methods. }\end{array}$ & $\begin{array}{l}\text { Accuracy } \\
\text { depends on } \\
\text { Sample data } \\
\text { used } \\
\text { construction of } \\
\text { dictionary. }\end{array}$ \\
\hline $\begin{array}{l}\text { Prasad } \\
\text { Reddy } \\
\text { P.V.G.D, } \\
\text { M. James } \\
\text { Stephen } \\
\text { [2013][21] }\end{array}$ & $\begin{array}{l}\text { Back } \\
\text { Propagation } \\
\text { Neural } \\
\text { Network } \\
\text { (BPNN). }\end{array}$ & $\begin{array}{l}\text { Better than } \\
\text { gradient } \\
\text { based } \\
\text { methods }\end{array}$ & $\begin{array}{l}\text { Not robust for } \\
\text { poor quality } \\
\text { fingerprints. }\end{array}$ \\
\hline
\end{tabular}

Parameter optimization plays very important role in increasing the efficiency of local and global ridge orientation estimation algorithms. This in turn improves the overall performance fingerprints recognition/identification systems.

Paper [19] provides guidelines for selecting optimal values for parameters: window size, number of smoothing cycles, and order of polynomial. This paper also gives directions to use of different types of polynomials. Most of the orientation estimation algorithms use singular points and sometimes to detect singular points ridge orientation estimates are used. 
Table 2. Comparative Analysis of global methods of ridge orientation estimation

\begin{tabular}{|c|c|c|c|}
\hline Authors & Approach & Advantages & Disadvantages \\
\hline $\begin{array}{l}\text { Jie Zhou } \\
\text { and } \\
\text { Jinwei Gu } \\
{[2004][3]}\end{array}$ & $\begin{array}{l}\text { Uses } \\
\text { combination } \\
\text { of } \\
\text { Polynomial } \\
\text { model and } \\
\text { Point Charge } \\
\text { (PC) model. }\end{array}$ & $\begin{array}{l}\text { Accurate. } \\
\text { Suitable for } \\
\text { plain arch } \\
\text { fingerprints, } \\
\text { for } \\
\text { misplaced or } \\
\text { false or } \\
\text { missing } \\
\text { singular } \\
\text { points. } \\
\text { Robust to } \\
\text { noise. } \\
\text { Moderate } \\
\text { computation } \\
\text { al cost. }\end{array}$ & $\begin{array}{l}\text { Does not work } \\
\text { for } \\
\text { Very poor } \\
\text { quality } \\
\text { fingerprints. } \\
\text { Depends } \\
\text { accurate } \\
\text { detection of } \\
\text { Singular } \\
\text { points. } \\
\text { Polynomial } \\
\text { order is a } \\
\text { critical factor. }\end{array}$ \\
\hline $\begin{array}{l}\text { Jinwei Gu, } \\
\text { Jie Zhou, } \\
\text { David } \\
\text { Zhang } \\
{[2003][4]}\end{array}$ & $\begin{array}{l}\text { A } \\
\text { combination } \\
\text { model. } \\
\text { Which } \\
\text { combines } \\
\text { polynomial } \\
\text { model and } \\
\text { Point charge } \\
\text { model }\end{array}$ & $\begin{array}{l}\text { Provides } \\
\text { accurate } \\
\text { orientation } \\
\text { estimation. } \\
\text { Robust } \\
\text { against } \\
\text { noise. } \\
\text { Low storage } \\
\text { cost. }\end{array}$ & $\begin{array}{l}\text { Does not work } \\
\text { for } \\
\text { Very poor } \\
\text { quality } \\
\text { fingerprints. }\end{array}$ \\
\hline $\begin{array}{l}\text { Wei-Yun } \\
\text { Yau, } \\
\text { Jun Li, } \\
\text { Han Wang } \\
{[2004][5]}\end{array}$ & $\begin{array}{l}\text { A nonlinear } \\
\text { phase } \\
\text { portrait } \\
\text { model. }\end{array}$ & $\begin{array}{l}\text { Ability to } \\
\text { model } \\
\text { orientations } \\
\text { of different } \\
\text { fingerprints. } \\
\text { Able to } \\
\text { model } \\
\text { multiple } \\
\text { singular } \\
\text { points. }\end{array}$ & $\begin{array}{l}\text { Computational } \\
\text { load is high } \\
\text { Storage } \\
\text { requirement is } \\
\text { more. }\end{array}$ \\
\hline $\begin{array}{l}\text { Sarat C. } \\
\text { Dass } \\
{[2004][7]}\end{array}$ & $\begin{array}{l}\text { Parametric } \\
\text { models. }\end{array}$ & $\begin{array}{l}\text { parallel } \\
\text { update of } \\
\text { both singular } \\
\text { points and } \\
\text { orientation } \\
\text { estimates. }\end{array}$ & $\begin{array}{l}\text { Computation } \\
\text { complexity is } \\
\text { high. }\end{array}$ \\
\hline $\begin{array}{l}\text { Yi Wang, } \\
\text { Jiankun Hu, } \\
\text { Damien } \\
\text { Phillips } \\
{[2007][9]}\end{array}$ & $\begin{array}{l}\text { Uses 2D } \\
\text { Fourier } \\
\text { expansion } \\
\text { (FOMFE) to } \\
\text { model ridge } \\
\text { orientation }\end{array}$ & $\begin{array}{l}\text { Singular } \\
\text { points are } \\
\text { not required. } \\
\text { Suitable for } \\
\text { all types of } \\
\text { fingerprints. } \\
\text { Low } \\
\text { computation } \\
\text { cost. }\end{array}$ & $\begin{array}{l}\text { Higher } \\
\text { polynomial } \\
\text { order leads to } \\
\text { over fitting and } \\
\text { Lower leads to } \\
\text { under fitting. } \\
\text { Do not provide } \\
\text { robustness } \\
\text { against noisy } \\
\text { fingerprints. }\end{array}$ \\
\hline $\begin{array}{l}\text { Surinder } \\
\text { Ram, Horst } \\
\text { Bischof, } \\
\text { Josef }\end{array}$ & $\begin{array}{l}\text { Legendre } \\
\text { Polynomials. }\end{array}$ & $\begin{array}{l}\text { Works for } \\
\text { noisy } \\
\text { fingerprints. }\end{array}$ & $\begin{array}{l}\text { Does not work } \\
\text { with unclear } \\
\text { ridges. }\end{array}$ \\
\hline
\end{tabular}

\begin{tabular}{|c|c|c|c|}
\hline $\begin{array}{l}\text { Birchbauer } \\
\text { [2009][15] }\end{array}$ & & & \\
\hline $\begin{array}{l}\text { Surinder } \\
\text { Ram, } \\
\text { HorstBisch } \\
\text { ofand } \\
\text { JosefBirchb } \\
\text { auer } \\
{[2010][16]}\end{array}$ & $\begin{array}{l}\text { Uses } \\
\text { Legendre } \\
\text { polynomials } \\
\text { at global } \\
\text { level and } \\
\text { zero pole } \\
\text { model for } \\
\text { singular } \\
\text { points. }\end{array}$ & $\begin{array}{l}\text { provides } \\
\text { compact } \\
\text { storage. }\end{array}$ & $\begin{array}{l}\text { Greater } \\
\text { computational } \\
\text { complexity. }\end{array}$ \\
\hline
\end{tabular}

Due to unavailability of original data and common test bed for experimenting and testing these methods, only qualitative comparative analysis is carried out. Information furnished in Table 1 and Table 2 is based on the results presented in the literature.

\section{CONCLUSION}

Ridge orientation is a very important feature that is used for represent ridge topology. Ridge orientation feature is used in enhancement, classification and segmentation etc. therefore reliable estimation of orientation is essential. Most of the orientation estimation methods are satisfactory for moderate noise levels. Researchers have attempted to improve the orientation estimation and proposed novel methods. This paper presents a review of state of the art techniques for ridge orientation estimation. This paper gives an insight into different approaches to orientation estimation techniques and also highlights their advantages and limitations. Our work also identifies some of the ridge orientation extraction methods as useful methods. They are Constrained Delaunay Triangulation (CDT) based interpolation method which is computationally simple, Non linear phase portrait model and

Parametric model gives accurate orientation estimate with an overhead of high computational complexity, and neural network based methods where neural network is trained for known ridge orientations.

\section{ACKNOWLEDGMENTS}

We would like to acknowledge Dr. H C Nagaraj, Principal, Nitte Meenakshi Institute of Technology for his valuable suggestions during our work.

\section{REFERENCES}

[1] Davide Maltoni, Dario Maio, Anil K. Jain, Salil Prabhakar, L. L. 2009. Handbook of Fingerprint Recognition.

[2] Asker M. Bazen, Sabih H. Gerez, "Systematic Methods for the Computation of the Directional Fields and Singular Points of Fingerprints", IEEE Transactions On Pattern Analysis And Machine Intelligence, Vol. 24, No. 7, July 2002

[3] Jie Zhou, Jinwei Gu, "A Model-Based Method for the Computation of Fingerprints' Orientation Field", IEEE Transactions On Image Processing, Vol. 13, No. 6, June 2004.

[4] J. Gu, J. Zhou, D. Zhang, "A combinational model for orientation field of fingerprints", Pattern Recogn,37(3), pp.543-553, 2004. 
[5] Wei-Yun Yau, Jun Li, Han Wang, J.2004. Nonlinear phase portrait modelling of fingerprint orientation. In proceedings of ICARCV on Control, Automation, Robotics and Vision.

[6] Asker M. Bazen, Niek J. Bouman, and Raymond N.J. Veldhuis, J 2004. A Multi-Scale Approach to Directional Field Estimation. In proceedings of RISC 2004.

[7] S. Dass, "Markov Random Field Models for Directional Field and Singularity Extraction in Fingerprint Images", IEEE Trans. Image Processing, vol. 13, no. 10, pp. 13581367,2004

[8] En Zhu, Jian-Ping Yin, Guo-Min Zhang, Chun-Feng Hu, J. 2006. Fingerprint Ridge Orientation Estimation Based On Neural Network, in proceedings Of Wseas Int. Conf. On Signal Processing, Robotics and Automation.

[9] Yi Wang, Jiankun Hu, Damien Phillips, “A Fingerprint Orientation Model Based On 2d Fourier Expansion (FOMFE) and Its Application to Singular-Point Detection and Fingerprint Indexing", IEEE Transactions On Pattern Analysis and Machine Intelligence, Vol. 29, No. 4, pp.573-585, 2007

[10] Yi Wang, Jiankun Hu, Fengling Han, "Enhanced gradient-based algorithm for the estimation of fingerprint orientation fields", Applied Mathematics and Computation, pp.823-833, vol. 185, 2007.

[11] Xudong Jiang, "Extracting image orientation feature by using integration operator", Pattern Recognition, pp.705 -717 , vol. 40, 2007

[12] Qinzhi Zhang, Hong Yan, "Fingerprint Orientation Field Interpolation Based On The Constrained Delaunay Triangulation", International Journal Of Information And Systems Sciences Volume 3, Number 3, Pages 438-452, 2007
[13] Luping Ji, Zhang Yi, "Fingerprint orientation field estimation using ridge projection", Pattern Recognition , Vol.41,pp.1491 - 1503, 2008.

[14] Carsten Gottschlich, Preda Mihailesc, Axel Munk, "Robust Orientation Field Estimation and Extrapolation Using Semilocal Line Sensors", IEEE transactions on Image and Signal Processing and analysis, pp. 529-533. 2009.

[15] Surinder Ram, Horst Bischof Josef Birchbauer, J.2009. Active fingerprint ridge orientation models. In proceedings of ICB '09(Third International Conference on Advances in Biometrics).

[16] Surinder Ram, Horst Bischof, Josef Birchbauer, "Modelling fingerprint ridge orientation using legendre polynomials", Pattern Recogn., vol 43,342-357, 2010.

[17] Limin Liu , Tian-Shyr Dai, "A Reliable Fingerprint Orientation Estimation Algorithm", Journal of Information Science and Engineering, vol. 27, pp. 353$368,2011$.

[18] S. Yoon, J. Feng, A. Jain, J.2011. Latent fingerprint enhancement via robust orientation field estimation. In proceedings of IJCB ( International Joint Conference on Biometrics.

[19] Francesco Turroni, Davide Maltoni, Raffaele Cappelli, Dario Maio, "Improving Fingerprint Orientation Extraction", IEEE Transactions On Information Forensics And Security, Vol. 6, No. 3, pp.1002-1013 2011.

[20] Jianjiang Feng, Jie Zhou, Anil K. Jain, "Orientation field estimation for latent fingerprint enhancement", IEEE Transactions on Pattern Analysis and Machine Intelligence, vol. 54, no. 4, pp. 925-940, 2013.

[21] Prasad Reddy P.V.G.D, M. James Stephen, “Towards Accurate Estimation of Fingerprint Ridge Orientation Using BPNN and Ternarization", IOSR Journal of Computer pp.2278-8727, Vol 13,. 2013. 